\title{
Planning of railway engineering works including rail traffic disruptions
}

\author{
Damian Kosicki* \\ Poznan University of Technology, Faculty of Civil and Environmental Engineering, Piotrowo 5, 60-965 Poznań, Poland
}

\begin{abstract}
The performance of railway engineering works involves the need to temporarily stop the train traffic along tracks covered by works. Track closures can be the reason for cancellation of selected trains, prolonging the travel time and changing the timetable. The issue of planning railway works in so-called operational closures in a short, weekly time span with minimized rail traffic disruptions is analysed in this paper. An optimization model has been presented, solution of which for a section of a railway line with a length of several kilometers and traffic of several hundred trains can be obtained in no more than a dozen or so minutes. The case study for maintenance works on the railway line No. 353 in Poland, on the section Poznań Wschód - Pobiedziska is presented.
\end{abstract}

\section{Introduction}

Maintenance, renewal and upgrading works on the railway line conducted with the use of specialized track machines, such as tamping machines, ballast cleaning machines or track renewal trains require the implementation of track closures for rail traffic [1,2]. Planning the above works on a section of a railway line with a high traffic intensity requires special consideration of train traffic hindrances caused by the implementation of closures [3]. In the literature, the problem of limitation of train traffic hindrances is most often formulated in the form of an optimization problem $[4,5,6,7]$.

A special subset of problems of this class, regarding the operational closure planning [8] in a very short, weekly time interval, is considered in this paper. Operational closures are implemented in case of necessity to change the planned dates of work realization. The necessity to quickly decide how the work should be realized is characteristic for such situations.

An aim of this study was to develop a method of operational closures planning, allowing to minimize the number of trains cancelled during railway engineering works. The scope of this paper includes a description of the applied method and a verification of it's utility to solve real life problems. The method uses author's optimization model, which can be classified as deterministic linear programming. IBM ILOG CPLEX software and simplex algorithm were used to solve optimization problem.

\section{Description of model applied}

An optimization model to support the work planning in a short time span, the purpose of which is to minimize the number of canceled trains, is proposed in this chapter. While developing the model, simplifications were adopted that enable the practical optimization problem to be solved in no more than a dozen minutes or so, as opposed to comprehensive models, for which it may take several hours to obtain a solution for a few dozen kilometers of railway line and several hundred trains [9]. The presented solution is a modification of the model presented in items $[10,11]$.

The analyzed area of railway network will be presented in form of the graph $G=(V, E)$, vertices of which will be posts, and its edges - routes connecting these posts. The set of route tracks will be marked as $R T$, and subsets of tracks on specific routes - as $R T_{v w}$, where $\{v, w\} \in E$. There will be analyzed $n$ time periods with a length of $k$, denoted as $c_{i}$, where $i \in\{1,2, \ldots, n\}$.

Three stages can be distinguished in the total time of any track closure [12]:

- preparation for works $(u)$,

- realization of main works $(v)$,

- completion of works $(w)$.

Assumption of a specific technology and organization of construction works allows determining the minimum length of each of these stages for each of the tracks $r t \in R T$, which will be marked $S_{x, r t}$, where $x \in\{u, v, w\}$. In addition, the possibilities of simultaneous execution of works on various tracks are limited by the resources of equipment and employees at the disposal of the contractor. The number of machines / teams at the disposal of the contractor for preparatory works will be marked as $M T_{x}$, where $x \in\{u, v, w\}$.

\footnotetext{
Corresponding author: damian.kosicki@put.poznan.pl
} 
It was assumed that the timetable before the commencement of works is known - in the entire analyzed time interval with the length $n \cdot k$ in the analyzed area runs a set of trains $T$. Knowledge of the timetable allows to determine, in which time interval each train $t \in T$ moves along the route $e \in E$ - this time interval will be marked as $o c_{e}^{t}$. The traffic capacity of the route $e$ through the time $k$ will be marked as cap $_{e}$.

The set of input data for the optimization model is presented in the table below.

Table 1. Input data for the optimization model

\begin{tabular}{|c|c|c|}
\hline Item & Description & Denotations \\
\hline 1. & Set of posts & $V$ \\
\hline 2. & $\begin{array}{l}\text { Set of routes connecting } \\
\text { posts }\end{array}$ & $E$ \\
\hline 3. & Set of route tracks & $R T$ \\
\hline 4. & $\begin{array}{l}\text { Set of route tracks } \\
\text { connecting the posts } v \\
\text { and } w\end{array}$ & $R T_{v w}\{v, w\} \in E$ \\
\hline 5 . & $\begin{array}{l}\text { Analysis time period } \\
\text { length (time step of } \\
\text { analyzes) }\end{array}$ & $k$ \\
\hline 6. & $\begin{array}{l}\text { Number of analyzed time } \\
\text { periods }\end{array}$ & $n$ \\
\hline 7. & $\begin{array}{l}\text { Time interval with the } \\
\text { number } i\end{array}$ & $\begin{array}{l}c_{i}=\langle k \cdot(i-1), k \cdot i) \\
i \in\{1,2, \ldots, n\}\end{array}$ \\
\hline 8. & $\begin{array}{l}\text { Set of all analyzed time } \\
\text { intervals }\end{array}$ & $C=\bigcup_{i=1}^{n} c_{i}$ \\
\hline 9. & Preparatory works & $u$ \\
\hline 10. & Main works & $v$ \\
\hline 11. & Finishing works & $w$ \\
\hline 12. & $\begin{array}{l}\text { Minimum time of works } \\
\text { in the track } r t\end{array}$ & $\begin{array}{l}S_{x, r t} \\
x \in\{u, v, w\}, r t \in R T\end{array}$ \\
\hline 13. & $\begin{array}{l}\text { Number of machines / } \\
\text { teams for works that the } \\
\text { contractor has at their } \\
\text { disposal }\end{array}$ & $\begin{array}{l}M T_{x} \\
x \in\{u, v, w\}\end{array}$ \\
\hline 14. & $\begin{array}{l}\text { Set of trains to be } \\
\text { released on the route in } \\
\text { the analyzed time period }\end{array}$ & $T$ \\
\hline 15. & $\begin{array}{l}\text { Time period in which, } \\
\text { according to the } \\
\text { timetable, the train } \mathrm{t} \\
\text { occupies the route } e\end{array}$ & $o c_{e}^{t}, t \in T, e \in E$ \\
\hline 16. & $\begin{array}{l}\text { Train travel time } \\
\text { between point } v \text { and } w\end{array}$ & $t t_{e}^{t}, t \in T, e \in E$ \\
\hline 17. & $\begin{array}{l}\text { Limitary (permissible) } \\
\text { participation of the } \\
\text { occupancy time of the } \\
\text { route } e \text { in the time period } \\
k\end{array}$ & cape $_{e}, e \in E$ \\
\hline 18. & $\begin{array}{l}\text { Parameter determining } \\
\text { whether in a given time } \\
\text { interval } c \text { the work } \\
\text { conducting is permissible } \\
\text { (value } 1 \text { ) or unacceptable } \\
\text { (value 0) }\end{array}$ & $Z Z^{c}, c \in C$ \\
\hline 19. & $\begin{array}{l}\text { Weight assigned to the } \\
\text { train } t \text {, depending on the } \\
\text { train category }\end{array}$ & $w^{t}, t \in T$ \\
\hline
\end{tabular}

Source: Own elaboration
Time intervals, in which individual tracks will be closed for the purposes of preparatory, main or finishing works, will be decision-making variables of the model. For each time interval $c \in C$ and for each route track $r t \in R T$ the binary decision-making variables $P_{x, r t}^{c}$ will determine if the route is planned to be closed for the purposes of execution of works of a given stage (value 1 ), or the track will not be closed at that time (value 0 ). In addition, auxiliary decision-making variables $E_{x, r t}^{c}$ will be introduced, defining the moment of completion of particular work stages $(x \in\{u, v, w\})$. Due to the introduction of track closures, when the traffic capacity of open tracks is insufficient, it may be necessary to cancel selected trains. The decision-making variable $\varphi_{t}$ will take the value 0 when the train is cancelled, otherwise it will take the value 1 .

The set of all decision-making variables of the optimization model is presented in the table below.

Table 2. Decision-making variables

\begin{tabular}{|c|c|c|}
\hline Item & Description & Denotations \\
\hline 1. & $\begin{array}{l}\text { Decision-making variable } \\
\text { taking the value } 1 \text {, when a } \\
\text { track is closed in the time } \\
\text { interval } c \text { for the needs of } \\
\text { carrying out works in the track } \\
r t \text { and the value } 0 \text { otherwise. }\end{array}$ & $\begin{array}{l}P_{x, r t}^{c} \in\{0,1\} \\
c \in C, r t \in R T, \\
x \in\{u, v, w\}\end{array}$ \\
\hline 2. & $\begin{array}{l}\text { Decision-making variable } \\
\text { determining the moment of } \\
\text { completion of works in the } \\
\text { track } r t \text {. }\end{array}$ & $\begin{array}{l}E_{x, r t} \\
r t \in R T \\
x \in\{u, v, w\}\end{array}$ \\
\hline 3. & $\begin{array}{l}\text { Decision-making variable that } \\
\text { takes the value } 0 \text {, when the } \\
\text { train } t \text { has to be cancelled, and } \\
\text { otherwise takes the value } 1 \text {. }\end{array}$ & $\begin{array}{l}\varphi^{t} \in\{0,1\} \\
t \in T\end{array}$ \\
\hline
\end{tabular}

Source: Own elaboration

The minimization of number of cancelled trains (the maximization of number of trains released onto routes) was proposed as the objective function of the optimization model, taking into account various weights for individual trains:

$$
\operatorname{Max} \sum_{t \in T} \varphi^{t} \cdot w^{t}
$$

The set of model constraints is shown below:

$\sum_{c \in C} P_{x, r t}^{c} \cdot k \geq S_{x, r t}, \forall x \in\{u, v, w\}, \forall r t \in R T$

$\sum_{x \in\{u, v, w\}} P_{x, r t}^{c} \leq 1, \forall r t \in R T, \forall c \in C$

$$
\sum_{r \in R T} P_{x, r t}^{c} \leq M T_{x}, \forall x \in\{u, v, w\}, \forall c \in C
$$

$P_{x, r t}^{c}=0, \forall x \in\{u, v, w\}, \forall r t \in R T, \forall c \in c_{i}: i \cdot k>E_{x, r t}$

$$
0 \leq E_{x, r t} \leq n \cdot k, \forall x \in\{u, v, w\}, \forall r t \in R T
$$




$$
\begin{gathered}
P_{v, r t}^{c}=0, \forall r t \in R T, \forall c \in c_{i}: i \cdot k \leq E_{u, r t} \\
P_{w, r t}^{c}=0, \forall r t \in R T, \forall c \in c_{i}: i \cdot k \leq E_{v, r t} \\
P_{x, r t}^{c} \leq Z Z^{c}, \forall x \in\{u, v, w\}, \forall r t \in R T, \forall c \in C \\
\sum_{t \in T: o c_{e}^{t}=c} t t_{e}^{t} \cdot \varphi^{t}+c a p p_{e} \cdot\left(\sum_{x \in\{u, v, w\}} P_{x r t}^{c}\right) \leq c a p_{e}, \\
\forall e=\{v, w\} \in E, \forall c \in C, \forall r t \in R T_{v w}
\end{gathered}
$$

The inequalities 2 enforce planning a time of track closures sufficient to complete all works. The inequality 3 concerns the possibility of realization of only one stage of work on one route track in a given time interval. The inequalities 4 introduce limitations resulting from the available number of machines and teams for the implementation of works. The equations 5 allow determining the moment of completion of each stage of works in each track, and the inequalities 6 enforce the completion of works during the analyzed time interval. The equations 7-8 determine the proper order of works the main works cannot start before the completion of preparatory works, and finishing works - before the completion of essential works. The inequalities 9 impose a restriction consisting in the inability to perform work at specific hours or days. For example, on sections of railway line running through urbanized areas the performance of works at night may be prohibited. The last inequality reflects the traffic capacity limitations the time of occupation of each track by train traffic or by construction works may not exceed a limit value [13].

\section{Discussion of adopted model simplifications}

In order to limit the time of solving the optimization problem, some simplifications were applied in this model in relation to the assumptions adopted in the models described in [10,11]. They are as follows:

- The model does not include any restriction consisting in definition of the minimum duration of travel of machines between individual route tracks. It is necessary each time to verify, whether the time interval between the completion and the commencement of works on another track is sufficient.

- The necessity to cancel trains results from the analysis of the use of traffic capacity in periods of time equal $k$. The model does not consider any specific timetable after the track closures have been planned, it is necessary to elaborate a closure specific timetable. However, this is in line with the current practice used by the Polish Railway Infrastructure Manager - PKP PLK S.A. [2]

- Only the traffic capacity of route tracks is analyzed in the model - the traffic capacity of stations is not considered. Therefore, after the closures have been planned, it is necessary to perform additional analyzes, e.g. simulations.

- The model assumes that there is a possibility of passing between the tracks No. 1 and 2 at each station.
Otherwise, the model should be supplemented with additional limitations.

- The objective function does not take into account the difficulties in the train traffic consisting in the extension of travel time due to the introduction of speed limits in the vicinity of ongoing works. It is justified to take them into account after the closure schedule has been elaborated.

\section{Case study}

This chapter presents a calculation example showing the possibility of using the model to solve the real life problem of planning the implementation of works on a section of railway line.

A section of railway line No. 353 in Poland between the stations Poznań Wschód and Pobiedziska together with the sections of railway line No. 003 Poznań Wschód Swarzędz and No. 356 Poznań Wschód - Czerwonak (Figure 1) were selected for the analysis.

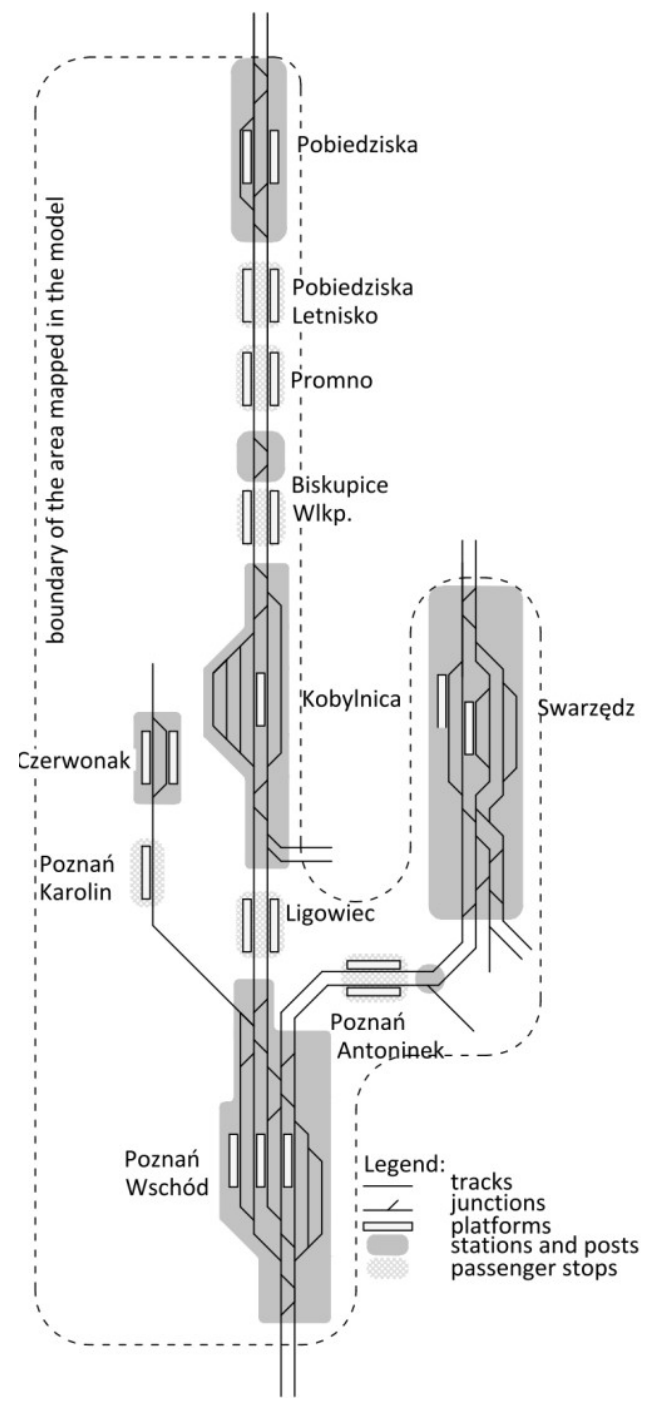

Fig. 1. Range of the railway network represented in the case study (source: Own elaboration)

The analyzed section of railway line no. 353 currently performs a special function in the Polish railway network 
- it is a fragment of the bypassing route for long-distance passenger trains running between Warsaw and Berlin, due to the modernization works on the main line E-20, currently being in progress. If it is necessary to carry out a maintenance works for maintaining the travel speed of $130-160 \mathrm{~km} / \mathrm{h}$, currently valid for passenger trains [14], the aspect of minimizing obstacles to train traffic will be of particular importance.

It was assumed that the scope of repair works on the Poznań Wschód - Pobiedziska section will include the following works:

- power switching off in the overhead system, access of machines to the place of work (preparatory works),

- track tamping together with adjustment in horizontal and vertical plane, replacement of individual sleepers, completion of ballast, periodic inspection of overhead system (main works),

- departure of machines from route tracks, power switching on in the overhead system (finishing works).

For the purpose of this calculation example, it was assumed that on each of the three routes: Poznan Wschód - Kobylnica, Kobylnica - Biskupice Wlkp. and Biskupice Wlkp. - Pobiedziska, the preparatory and main works would last 1 hour. The duration of essential works could be estimated basing on capacities of specific machines and teams, prevailing local conditions and effectiveness of closure time use. In the calculation example, 8 variants were analyzed, differing in the duration of essential works and permissible working hours. In addition, the comparative variant W0, not taking into account the work conducting, was also presented. For each variant, as a result of optimization, a schedule of track closures necessary to carry out works was obtained, for which the number of canceled trains is the smallest, while maintaining a number of restrictions.

The description of input data invariable for each analyzed variant is presented below:

- length of the railway line no. 353 mapped in the model: $21.795 \mathrm{~km}$,

- number of stations: 4 ,

- number of routes: 3 ,

- number of route tracks on each route: 2 ,

- length of the analysis time period: 1 hour,

- number of analyzed time periods: 168 ,

- total time horizon of the analysis: 7 days,

- time for preparatory work in each track: 1 hour,

- time of finishing works in each track: 1 hour,

- number of trains in the base timetable for the analyzed time interval: 938 ,

- limitary share of route occupancy time in 1 hour: 45 minutes.

In addition, the input data that distinguish individual variants are shown in the following table:
Table 3. Decision-making variables

\begin{tabular}{|c|c|c|c|}
\hline Variant & $\begin{array}{c}\text { Duration of } \\
\text { main works } \\
\text { [hours] }\end{array}$ & $\begin{array}{c}\text { Minimum } \\
\text { total track } \\
\text { closure } \\
\text { duration } \\
\text { [hours] }\end{array}$ & $\begin{array}{c}\text { Permissible working } \\
\text { hours }\end{array}$ \\
\hline W0 & 0 & 0 & - \\
\hline W1 & 8 & 10 & all day \\
\hline W2 & 10 & 12 & all day \\
\hline W3 & 12 & 14 & all day \\
\hline W4 & 14 & 16 & all day \\
\hline W1N & 8 & 10 & except 22:00-6:00 \\
\hline W2N & 10 & 12 & except 22:00-6:00 \\
\hline W3N & 12 & 14 & except 22:00-6:00 \\
\hline W4N & 14 & 16 & except 22:00-6:00 \\
\hline
\end{tabular}

Source: Own elaboration

The optimization problem was solved using the IBM ILOG CPLEX software. The model size for the data considered was as follows:

- number of constraints: 22,788

- number of variables: 9057.

A computer with an Intel Core i5 $2 \times 2.30 \mathrm{GHZ}$ processor with $8.00 \mathrm{~GB}$ of RAM was used. The time of finding the optimal solution varied, depending on the variant, from less than a minute to 10 minutes. To illustrate the course of optimization, the following figure shows the relationship between the value of the objective function and the time of optimization for the example of variants $\mathrm{W} 0, \mathrm{~W} 1$ and $\mathrm{W} 4 \mathrm{~N}$.

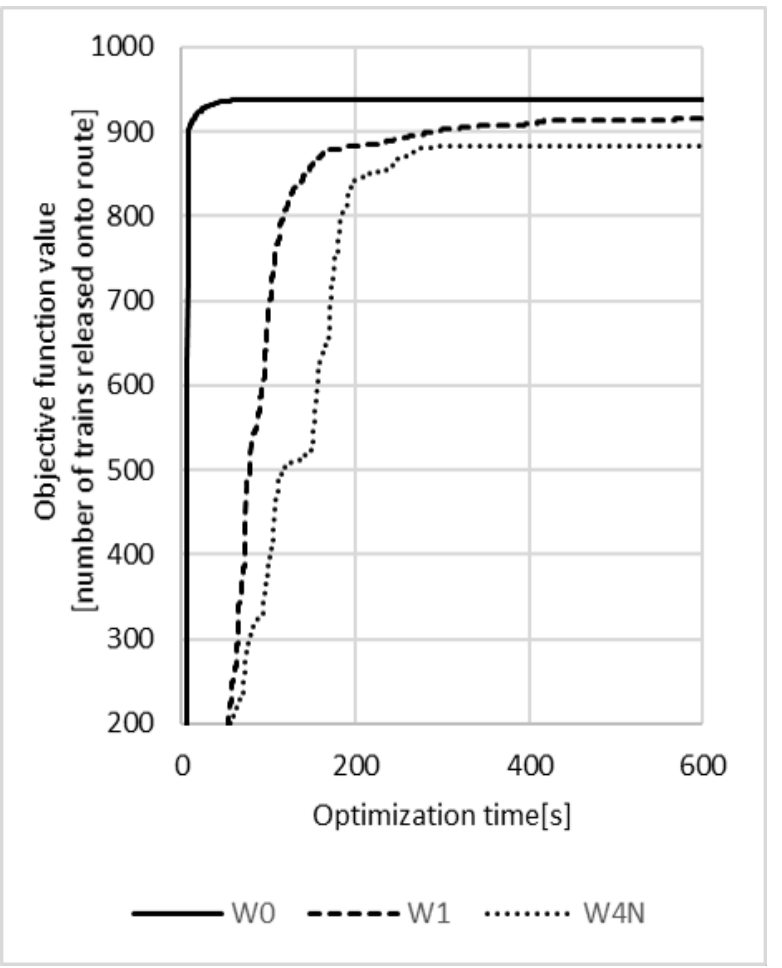

Fig. 2. The objective function value (number of trains released onto route) throughout the optimization time for the variants W0, W1 and W4N (Source: Own elaboration based on IBM ILOG CPLEX engine logs) 
The number of trains released onto route and the number of cancelled ones, obtained in particular variants, are presented in the table and in the figure below.

Table 4. Computational results

\begin{tabular}{|l|c|c|}
\hline Variant & $\begin{array}{c}\text { Number of } \\
\text { trains released } \\
\text { onto route }\end{array}$ & $\begin{array}{c}\text { Number of } \\
\text { canceled trains }\end{array}$ \\
\hline W0 & 938 & 0 \\
\hline W1 & 915 & 23 \\
\hline W2 & 911 & 27 \\
\hline W3 & 911 & 27 \\
\hline W4 & 909 & 29 \\
\hline W1N & 908 & 30 \\
\hline W2N & 906 & 32 \\
\hline W3N & 898 & 40 \\
\hline W4N & 884 & 54 \\
\hline
\end{tabular}

Source: Own elaboration based on IBM ILOG CPLEX engine $\log S$

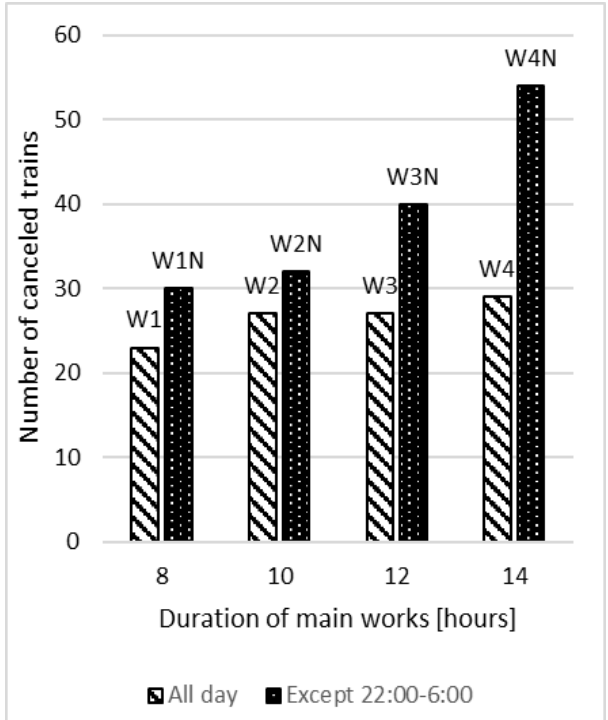

Fig. 3. Number of cancelled trains in different variants (Source: Own elaboration based on IBM ILOG CPLEX engine $\operatorname{logs})$

The result of optimization is also the schedule of planned track closures and the use of traffic capacity of individual route tracks taking into account the need for two-way traffic on one track. An exemplary schedule for variant $\mathrm{W} 1$ is shown in the figure 4 and 5 . It should be noted that the restrictions 2 in the model are formulated as inequalities; as a result, in the solution obtained on some tracks, the time of track closures is longer than the time of works, but this does not cause the necessity to cancel additional trains (does not affect the value of the objective function).

\section{Conclusions}

The following conclusions can be formulated on the basis of conducted research:

- Using the proposed optimization model, it is possible to plan operational closures for the needs of the works on a railway line section in no more than a dozen minutes or so, what is a prerequisite for a practical use of the model under real operational conditions.

- The model allows analyzing the consequences of choosing a particular technology and organization of works and the resulting closure time for the number of cancelled trains. For each declared duration of work realization, a schedule of track closures is prepared that involves the minimum number of cancelled trains.

- The results obtained for case study show the consequences of different efficiency of track closure utilization.

- It is necessary to conduct further analyzes regarding the impact of the complexity of the considered case on the time of solving the optimization problem.

- It is necessary to conduct further analyzes regarding the assessment of the consequences of adopting simplified assumptions for the model described in the chapter 3.

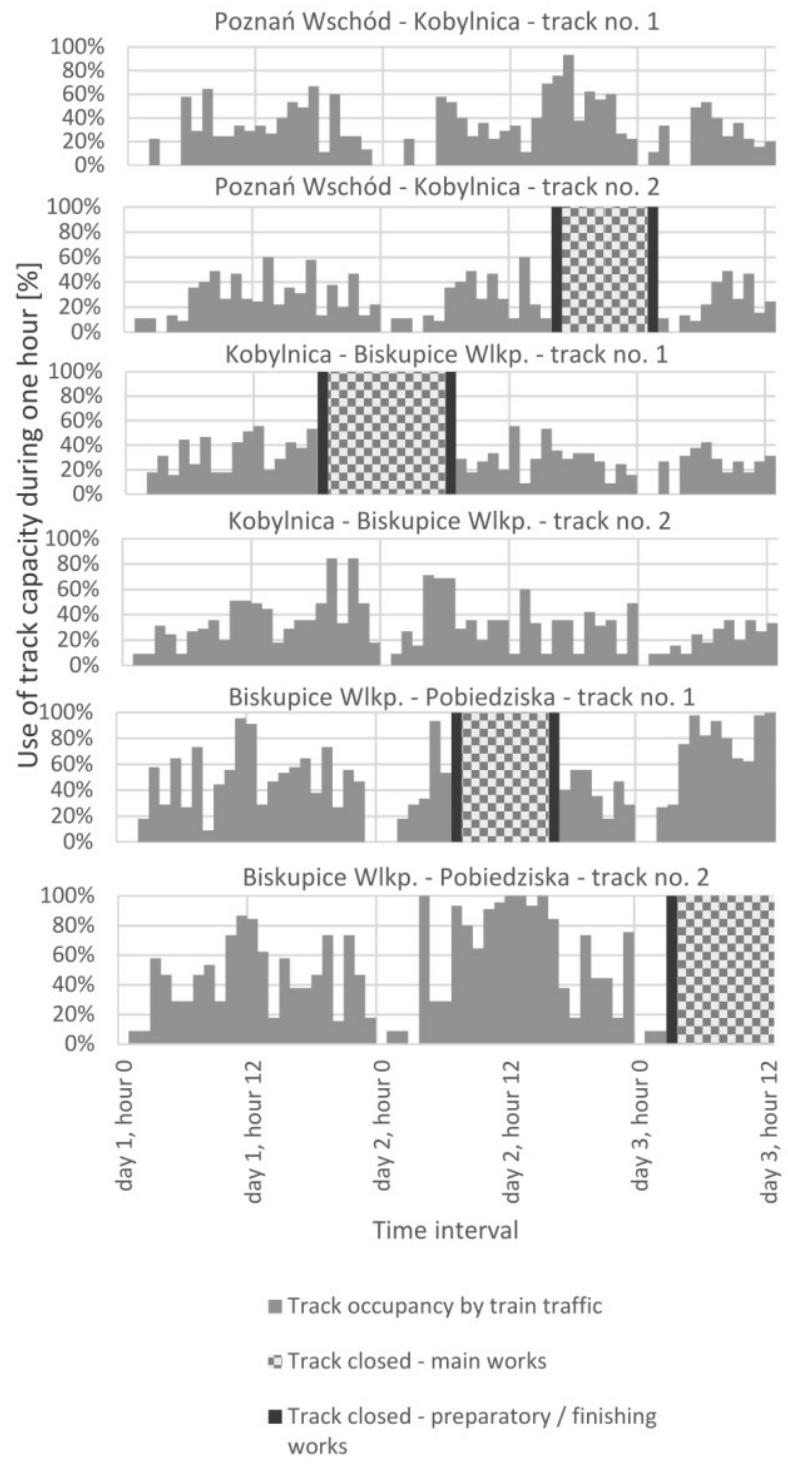

Fig. 4. Scheduled track closures and use of traffic capacity of particular route tracks in the variant $\mathrm{W} 1$ - the solution with the smallest objective function value (part 1) (Source: Own elaboration based on IBM ILOG CPLEX engine logs) 


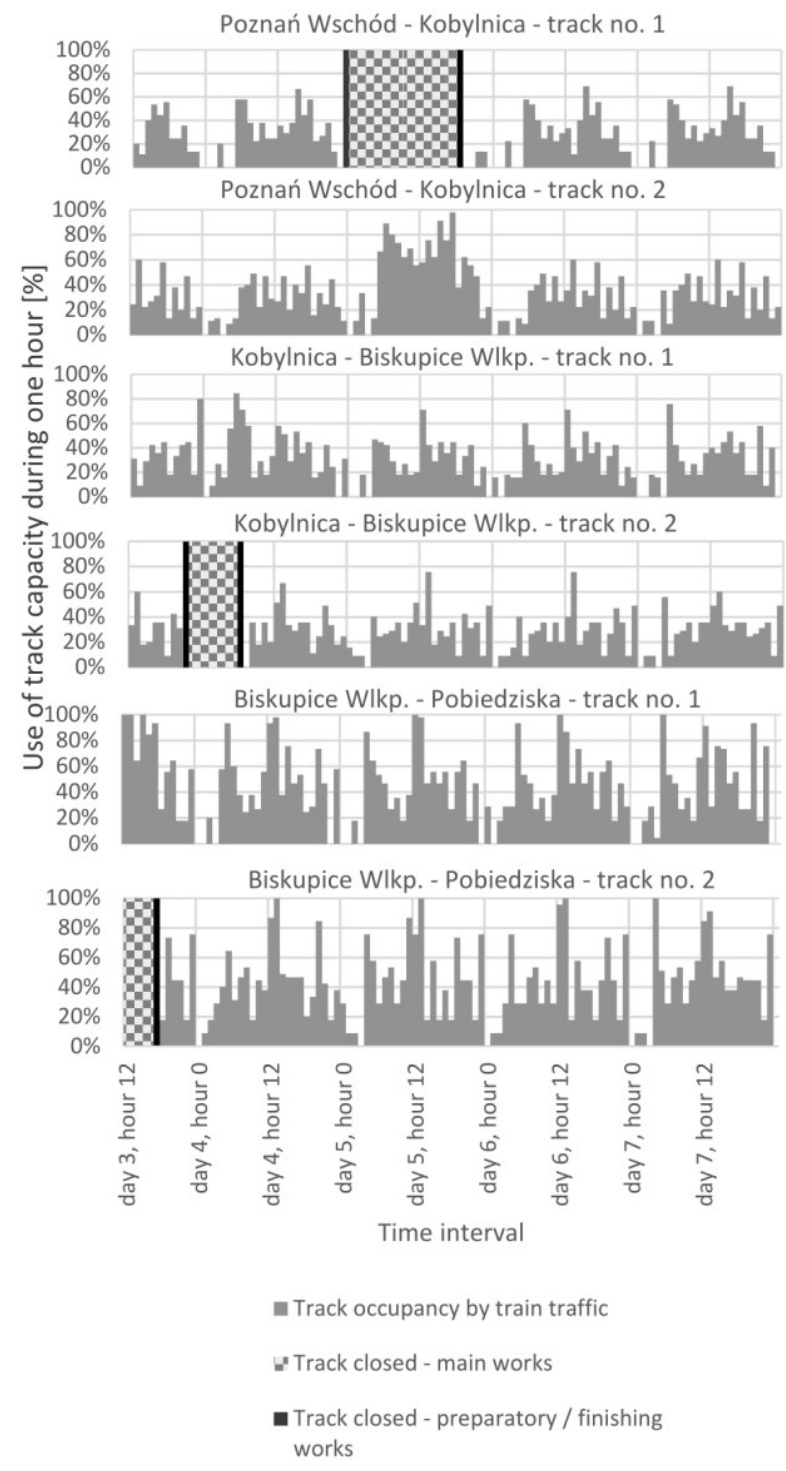

Fig. 5. Scheduled track closures and use of traffic capacity of particular route tracks in the variant $\mathrm{W} 1$ - the solution with the smallest objective function value (part 2) (Source: Own elaboration based on IBM ILOG CPLEX engine logs)

\section{References}

1. PKP Polskie Linie Kolejowe S.A., Warunki techniczne utrzymania nawierzchni na liniach kolejowych Id-1, 2005.

2. PKP Polskie Linie Kolejowe S.A., Zasady organizacji i udzielania zamknięć torowych Ir-19, 2015.

3. P. Vansteenwegen, T. Dewilde, S. Burggraeve, D. Cattrysse, European Journal of Operational Research, 3, 111-123, 2013.

4. L. Caetano, P. Teixeira, Journal of Transportation Engineering, 139, 941-948, 2013.

5. T. Lidén, M. Joborn, Transportation Research Part C, 74, 327-347, 2017.

6. F. Peng, Y. Ouyang, Computer-Aided Civil and Infrastructure Engineering, 29, 235-247, 2014.
7. M. Forsgren, M. Aronsson, S. Gestrelius, Journal of Rail Transport Planning \& Management, 3, 111-123, 2013.

8. D. Kosicki, Archives of Institute of Civil Engineering [In Polish], 25, 209-220, 2017.

9. T. Lidén, M. Joborn, Transportation Research Part C, 74, 327-347, 2017.

10. D. Kosicki, E. Plucińska, Conference Proceedings "Transport Problems, V International Symposium of Young Researchers”, 718-727, 2016.

11. D. Kosicki, 5th International Conference Advanced Rail Technologies, 81-82, 2016.

12. T. Lidén, M. Joborn, Journal of Rail Transport Planing \& Management. 6, 32-47, 2016.

13. M. Abril, F. Barber, L. Ingolotti, M. A. Salido, P. Tormos, A. Lova, Transportation Research Part E: Logistics and Transportation Review, 44, 774-806, 2008.

14. PKP Polskie Linie Kolejowe S.A., Regulamin Sieci 2017/2018. 